\title{
Problemática metodológica em jornalismo impresso
}

Gislene Silva

\section{Resumo:}

Alguns investigadores brasileiros vêm, com mais ênfase nos últimos anos, rastreando o perfil da pesquisa em jornalismo no Brasil. As abordagens são quase de escopo abrangente, com levantamentos de temas, suportes tecnológicos e linhas de pesquisa. Gostaria de partir desses conjuntos de trabalhos propostos em macro-análises para, especificamente, problematizar opções metodológicas em estudos de jornalismo que tomam como base matérias jornalísticas impressas.

\section{Palavras Chave:}

metodologia, impresso, texto jornalístico, teoria do jornalismo

\section{Abstract:}

Some brazilian researchers have been tracing, more expressively in the last years, the profile of the journalism research in Brazil. The approaches have a broad aim, with subject survey, technological support and research lines. I would like to start from these conjunct of works proposed in macroanalysis to question, specifically, methodological options in journalism studies that take as basis newspaper articles.

\section{Keywords:}

methodology, press, journalistic text, journalism theory

Alguns investigadores brasileiros vêm, com mais ênfase nos últimos anos, rastreando o perfil da pesquisa em jornalismo no Brasil. Esses rastreamentos nos oferecem um quadro geral em termos de questões, temas e metodologias, com o propósito de explicitar o status científico do Jornalismo dentro do grande campo da Comunicação. As análises são geralmente em termos de segmentos privilegiados como opção de estudo. Gostaria de partir desses conjuntos de trabalhos propostos em macro-análises para, especificamente, problematizar opções metodológicas em estudos de jornalismo que tomam como base matérias jornalísticas impressas.

De modo muito amplo, incluindo toda a pesquisa em Jornalismo, os primeiros levantamentos tratam de identificar, de maneira muito larga, cenários gerais da pesquisa, seja no rastreamento de linhas de pesquisa, de programas de pós-graduação ou de trabalhos publicados ou apresentados em congressos. Um desses esforços, organizado por Christa Berger (2002: 144), sugere tendências de linhas de investigação, visualizadas em publicações sobre imprensa no país. 


\begin{tabular}{|l|l|}
\hline $\begin{array}{l}\text { 1 História do jornalismo, } \\
\text { história dos jornais }\end{array}$ & $\begin{array}{l}\text { grande incidência; corte historiográfico, com registro da } \\
\text { imprensa regional e história dos jornais, tanto pela } \\
\text { história econômica e política (Taschner, 1992; Faro, } \\
\text { 1999; Wainberg, 1997) como pela nova história ou } \\
\text { história cultural (Braga, 1991; Oliveira, 1993; França, } \\
\text { 1998) }\end{array}$ \\
\hline $\begin{array}{l}\text { descrição historiográfica (Ferreira, 1978); imprensa } \\
\text { popular (Gomes, 1990); imprensa alternativa (kucinsk, } \\
\text { popular } \\
\text { 1991); questões conceituais (Fadul e Lins da Silva, 1982, } \\
\text { e Festa, 1986) }\end{array}$ \\
\hline ou alternativo & $\begin{array}{l}\text { produção significativa, feita por jornalistas com intenção } \\
\text { de ensinar fazer (Bahia, 1971; Burnett, 1968; Erbolato, } \\
\text { 1978; Kotscho, 1989) e outros de ensino técnico (Ferrari e } \\
\text { Sodré, 1986; Lage, 1979) }\end{array}$ \\
\hline $\begin{array}{l}\text { 4 Análise } \\
\text { da profissão e }\end{array}$ & $\begin{array}{l}\text { responsabilidade social (Medina, 1982), crítica } \\
\text { (Marcondes Filho, 2000); rotinas de trabalho (Travancas, } \\
\text { 1993); Ribeiro, 1994) }\end{array}$ \\
do profissional & $\begin{array}{l}\text { segunda grande incidência, com enfoque quantitativo da } \\
\text { análise de conteúdo (Marques de Melo, 1972; } \\
\text { D’Azevedo, 1982) ou com sustentação nas teorias da } \\
\text { linguagem, no estudo da relação entre as notícias e os } \\
\text { estudos do discurso }\end{array}$ \\
\hline $\begin{array}{l}\text { 6 Jorálise de coberturasa no jornalismo digital e informação on line, com } \\
\text { eletrônico/web }\end{array}$ & $\begin{array}{l}\text { atenção às mudanças no pólo da produção e distribuição } \\
\text { da notícia, e à condição da notícia em tempo real }\end{array}$ \\
\hline Outras & $\begin{array}{l}\text { outras pesquisas mais pontuais: noção de verdade no fato } \\
\text { jornalístico (Wilson Gomes, 1991, 1993); antropologia } \\
\text { das notícias para compreendê-las como culturalmente } \\
\text { significativas, dotadas de matéria simbólica e mítica; } \\
\text { teoria do jornalismo: jornalismo como modo de } \\
\text { conhecimento (Genro Filho, 1987; Meditsch, 1992); } \\
\text { Marcondes Filho (1984, e 1993) }\end{array}$ \\
\hline
\end{tabular}

Em síntese, Christa Berger observa que

Os estudos sobre a imprensa têm inclinação crítica, enfatizando a forma de propriedade, a opção mercadológica e a interferência destas condições nas coberturas. Os estudos situam o jornalismo na história, relacionando-o à forma autoritária do país; buscam salientar experiências - também historicamente datadas - de modos alternativos e populares de fazer de jornalismo; analisam coberturas, notícias, editoriais para esclarecer os sentidos propostos, os protagonistas envolvidos e a presença dos contextos; decrevem rotinas de trabalho buscando indicadores da sua formação textual; chama atenção para a função ora de ocultamento, ora de exposição das coisas; e, dizem da sua responsabilidade para a democratização do país (...) (BERGER, 2002:150).

Esse conjunto de questões teóricas, ainda segundo Berger, se disporia sobre dois eixos: o «eixo da linguagem», tratando da formulação textual, e o eixo da história política, na relação do Estado com a sociedade civil.

Em outra análise, Elias Machado se propõe a organizar as principais linhas de pesquisa no campo do jornalismo no período de três décadas (revista e-compos 2004): 


\begin{tabular}{|c|c|}
\hline $\begin{array}{l}1 \text { História do } \\
\text { Jornalismo }\end{array}$ & $\begin{array}{l}\text { mais antiga linha de pesquisa existente no país, com trabalhos } \\
\text { isolados pioneiros de Alfredo de Carvalho, Hélio Vianna e } \\
\text { Nélson Werneck Sodré. Núcleos na Usp, UERJ, UFF e UMESP }\end{array}$ \\
\hline $\begin{array}{l}2 \text { Teorias } \\
\text { do Jornalismo }\end{array}$ & $\begin{array}{l}\text { com os trabalhos pioneiros de Barbosa Lima Sobrinho, Carlos } \\
\text { Rizzini, Antonio Olinto, Alceu de Amoroso Lima, Danton } \\
\text { Jobim e Luiz Beltrão.Numa segunda etapa, destacam-se os } \\
\text { pesquisadores oriundos de cursos de pósgraduação como José } \\
\text { Marques de Melo, Muniz Sodré, Nilson Lage, Ciro Marcondes } \\
\text { Filho, Cremilda Medina e Adelmo Genro Filho. Hoje os estudos } \\
\text { mais consistentes de Teorias do Jornalismo estão vinculados aos } \\
\text { pesquisadores da USP, UFBa, UnB e UFSC }\end{array}$ \\
\hline $\begin{array}{l}3 \text { Análise } \\
\text { do discurso }\end{array}$ & $\begin{array}{l}\text { trabalhos pioneiros de AntônioFausto Neto, primeiro na UnB, } \\
\text { depois na UFRJ e hoje na Unisinos. Os trabalhos mais } \\
\text { consistentes são liderados por grupos na Unisinos, na UFRJ, } \\
\text { PUC-SP,UFRGS e na UFBa }\end{array}$ \\
\hline $\begin{array}{l}4 \text { Produção } \\
\text { da Notícia }\end{array}$ & $\begin{array}{l}\text { trabalhos pioneiros na PUC-RS; PUC-SP, UFF, UnB e USP. } \\
\text { Hoje, os principais pesquisadores estão na PUC-SP, } \\
\text { USP, UFPE, UnB e Federal Fluminense }\end{array}$ \\
\hline 5 Recepção & $\begin{array}{l}\text { trabalhos pioneiros na USP e na UFRJ. Os grupos mais } \\
\text { consistentes estão na USP, UFRJ, Unisinos, UFRGS e UFBa }\end{array}$ \\
\hline 6 Jornalismo Digital & $\begin{array}{l}\text { trabalho pioneiro dos pesquisadores da UFBa e da } \\
\text { ECA. Hoje os grupos mais consistentes estão na UFBa, na ECA } \\
\text { e na UnB }\end{array}$ \\
\hline 7 Teorias & $\begin{array}{l}\text { trabalho que ganha corpo nos programas de pós da UnB e na } \\
\text { USP }\end{array}$ \\
\hline $\begin{array}{l}8 \text { Jornalismo } \\
\text { Especializado }\end{array}$ & $\begin{array}{l}\text { pioneirismo na ECA e na Metodista. Principais núcleos de } \\
\text { pesquisa, principalmente jornalismo científico e empresarial na } \\
\text { USP, UMESP e PUC-RS. Núcleos de pesquisa na UnB, na } \\
\text { UFPE e na Unicamp }\end{array}$ \\
\hline
\end{tabular}

No levantamento elaborado por Márcia Benetti Machado (2004)(2), a respeito dos programas de pósgraduação do país, temos outras nove categorias, que abrangem tanto temas, suportes, teorias ou metodologias:

\begin{tabular}{|l|}
\hline 1 História do jornalismo \\
\hline 2 Estudos de linguagem \\
\hline 3 Produção da notícia e processos jornalísticos \\
\hline 4 Estudos de recepção \\
\hline 5 Jornalismo digital \\
\hline 6 Ética e jornalismo \\
\hline 7 Jornalismo e educação \\
\hline 8 Teorias do jornalismo \\
\hline $\begin{array}{l}\text { 9 Jornalismo especializado (científico, ambiental, } \\
\text { político, econômico, cultural etc) }\end{array}$ \\
\hline
\end{tabular}

Essas leituras gerais das produções acadêmicas do campo do jornalismo, sem foco especificado, também se dão no levantamento elaborado por Eduardo Medistsch e Mariana Segala (2005) a partir dos trabalhos apresentados em seis congressos nacionais (Compós, Intercom e SBPJor, nos anos de 2003 e 2004): 


\begin{tabular}{|l|}
\hline 1 História do Jornalismo \\
\hline 2 Estudos da linguagem e da narrativa \\
\hline 3 Processo de produção da notícia \\
\hline 4 Teorias do jornalismo \\
\hline 5 Recepção e efeitos \\
\hline 6 Estudos da profissão, \\
\hline 7 Novas tecnologias \\
\hline 8 Ética jornalística \\
\hline 9 Crítica do Jornalismo \\
\hline 10 Jornalismo e educação \\
\hline 11 Ensino do jornalismo \\
\hline Outros \\
\hline
\end{tabular}

Mais recentemente, José Marques de Melo (2006: pp 22-34) elencou quatro grandes tendências da pesquisa em jornalismo no Brasil, e o fez a partir de uma leitura histórica, de como a pesquisa em jornalismo se desdobrou e se consolidou ao longo do tempo:

\begin{tabular}{|c|c|}
\hline $\begin{array}{l}1 \text { corrente } \\
\text { ético-social }\end{array}$ & $\begin{array}{l}\text { de início estudos sobre deontologia e legislação, códigos de ética } \\
\text { da profissão e depois sobre da função social do jornalismo como } \\
\text { serviço público em favor da democracia. }\end{array}$ \\
\hline $\begin{array}{l}2 \text { corrente } \\
\text { técnico-editorial }\end{array}$ & $\begin{array}{l}\text { no contexto pós-golpe de } 1964 \text { e em decorrência da modernização } \\
\text { dos meios de comunicação no país, os estudos sobre as técnicas } \\
\text { jornalísticas e melhoria dos padrões editoriais. Surgimento dos } \\
\text { «Cadernos de Jornalismo», do Jornal do Brasil, dos volumes da } \\
\text { série «Bloch Comunicação», da Editora Bloch e da publicação } \\
\text { «Aldeia Global» da Rede Globo de Televisão e livros e textos } \\
\text { produzidos dentor das universidades sobre princípios e técnicas do } \\
\text { jornalismo em diferentes suportes. }\end{array}$ \\
\hline $\begin{array}{l}3 \text { corrente } \\
\text { político-ideológica }\end{array}$ & reflexões sobre indústria cultural, ideologia da notícia. \\
\hline $\begin{array}{l}4 \text { corrente } \\
\text { crítico-profissional }\end{array}$ & $\begin{array}{l}\text { novas perspectivas sobre a profissionalização, especificidade do } \\
\text { jornalismo como campo profissional e como objeto acadêmico, } \\
\text { arsenal metodológico para alimentado pelas ciências humanas pra } \\
\text { traçar contornos da profissão e resgatar suas dimensões sociais e } \\
\text { políticas. }\end{array}$ \\
\hline
\end{tabular}

Essas grandes apreensões entrecruzadas ao mesmo tempo por temas, áreas, objetos de trabalho, opções metodológicas, programas e linhas de pesquisa dificultam a compreensão dos resultados e a compreensão da problemática da investigação no campo do jornalismo. Agora, em 2007, porém, com base nos trabalhos apresentados no núcleo de pesquisa em jornalismo da Intercom, levantando artigos dos dez últimos anos, Antonio Holfeldt e Aline Srelow optaram por uma abordagem mais focada e revelam, a partir da análise de conteúdo, uma série de dados que desenham o panorama especificamente metodológico das pesquisas em jornalismo no país.

Entre as conclusões do trabalho divulgado no encontro nacional da SBPJor de 2007, cujo tema foi justamente "Metodologia de Pesquisa em Jornalismo" (3), apontam um primeiro dado preocupante: 181 dos 341 
trabalhos de natureza empírica apresentados não trazem sequer a menção à metodologia de pesquisa empregada (4). Classificando essas metodologias, cujas incidências se assemelham àquelas que os pesquisadores puderam inferir na leitura dos trabalhos que não explicitaram suas escolhas, os pesquisadores chegaram aos seguintes resultados sobre as estratégias metodológicas mais utilizadas (somando as explicitadas com as inferidas):

\begin{tabular}{|l|l|}
\hline METODOLOGIAS & MENÇÕES \\
\hline Análise do discurso & 121 \\
\hline Análise de conteúdo & 79 \\
\hline Estudo de caso & 53 \\
\hline Método comparativo & 48 \\
\hline Entrevista & 36 \\
\hline Pesquisa histórica & 17 \\
\hline Pesquisa documental & 14 \\
\hline Observação participante & 13 \\
\hline Método biográfico & 11 \\
\hline Demais métodos & Menos de 10 \\
\hline
\end{tabular}

Além da falta de preocupação na explicitação da metodologia utilizada, os autores criticam nos trabalhos analisados os equívocos nas denominações das metodologias escolhidas e a confusão permanente entre opções teóricas e metodológicas.

Ainda dentro das conclusões a que chegaram os dois pesquisadores, quero destacar duas questões a partir das quais pretendo aprofundar as reflexões sobre a problemática da pesquisa em jornalismo. Primeiramente, a predominância de metodologias voltadas ao estudo do texto jornalístico ou, se pudermos dizer de outro modo, a preponderância dos estudos de matérias jornalísticas sobre as demais instâncias do processo jornalístico, como produção e recepção. Depois, a falta de precisão ou até de clareza quanto às denominações das metodologias utilizadas. Os autores dão exemplos: «narratividade», que deveria ser abordada enquanto foco de estudo e não enquanto método, pois que geralmente vem sendo estudada através da análise do discurso; e «análise semiótica», que deveria ser entendida muito mais enquanto uma teoria do que um método. Diria até de uma falta de coerência entre a metodologia dita e a praticada.

Fazendo um cruzamento entre essas duas questões, predominância da pesquisa com textos jornalísticos e dificuldades de sistematização no emprego de metodologias, gostaria de acentuar o debate. Seja em TV, rádio ou impresso, por que a maioria das pesquisas recorre a produtos jornalísticos (informativo, opinativo e/ou reportagens)? Será somente porque ainda não temos consolidadas tradições de pesquisa nos campos da produção e da recepção? Considerando essa uma pertinente hipótese, suponho, no entanto, que algumas outras variáveis interferem nessa escolha: acesso ao objeto de trabalho - é mais viável gravar telejornais e radiojornais, guardar exemplares de revistas, recortar jornais impressos ou arquivar páginas da internet do que conseguir autorização das empresas para se pesquisar dentro das redações ou mesmo a disponibilidade dos profissionais para entrevista e do que também entrevistar leitores; custos da pesquisa - é mais barato investigar produtos do que processo de produção ou modos de recepção, posto que muitos dos resultados divulgados em congressos ou publicados são fruto de trabalho individual e não do de equipes; tempo de duração da pesquisa - trabalhos que resultam de dissertações e teses ou que envolvam pesquisadores de diferentes instituições e/ou contam com fomento costumam trazer investigações com procedimentos metodológicos mais múltiplos ou mesmo investidos em mais de uma instância do processo jornalístico, como é o caso, somente a título de exemplo, da pesquisa de Aline Strelow (2007) sobre "Análise Global de 
Processos Jornalísticos", da reflexão de Miguel Rodrigo Alsina no encontro da SBPJor em 2007 ("La sociosemiótica como método de investigación em periodismo") e de outras investigações que se propõem a analisar a complexidade e abrangência de fenômenos comunicativos específicos, como a grande pesquisa feita sobre a telenovela brasileira por Maria Immacolata Vassallo de Lopes, Silvia Simões Borelli e Vera Resende (2002) (5), que opta por uma estratégia multimetodológica e interseccional entre estudo de recepção e a perspectiva teórica das mediações e da ficcionalidade, de modo a analisar a produção da telenovela, o produto telenovela e a recepção de telenovelas. (Importante lembrar que as redes de pesquisa que estão sendo criadas na área deverão modificar esta situação, minizando os aspectos negativos dessas variáveis, especialmente os de custos, força de trabalho e tempo, que se compartilhados deixam de ser entraves e passam a ser boas soluções.)

Pelo que foi até aqui demonstrado, supõe-se que a pesquisa acadêmica vem demandando investigações mais pontuais sobre metodologias aplicadas ao estudo do jornalismo. De 2004 a 2007, alguns livros publicados na área tentam organizar, adaptar ou sugerir metodologias e técnicas próprias para se pesquisar o jornalismo (6). Também em congressos começam a surgir com mais freqüência trabalhos com interesse em metodologias específicas como, por exemplo: na investigação do processo de produção em telejornalismo (ver textos de Antonio Vizeu sobre «newsmaking» em jornalismo de tv); na reflexão sobre o estudo de caso e suas implicações epistemológicas no campo da comunicação - e por extensão no jornalismo - (ver textos de José Luiz Braga); ou estudos que estabelecem metodologias bem definidas para o tratamento de matérias jornalísticas impressas (como faz Cristina Ponte quando propõe um protocolo de análise de conteúdo específico para texto jornalístico (7)). Alguns segmentos se destacam nesse interesse por metodologias aplicadas ao jornalismo, como aquelas produções acadêmicas sobre fluxos internacionais de informação, história do jornalismo, técnicas e métodos para análise de imagens na mídia, estudo da recepção, e usos do webjornalismo (ver conferência de abertura de Maxwell MacCombs no último encontro da SBPjor, "Creating a new news: opportunities in the internet for broader and deeper journalism"). Também há as que se dedicam a fazer arqueologia de conceitos importantes para a pesquisa em jornalismo, seja de originários de outros campos, como o conceito de enquadramento/framing, ou conceitos da teoria da notícia, como valores-notícia e noticiabilidade.

Porém, parece se repetir no campo da pesquisa em Jornalismo o que muito se deu e se dá ainda hoje nas investigações sobre Comunicação: uma divisão das pesquisas por meios tecnológicos (rádio, foto, impresso, tv, cinema e agora web) - que se reflete com visibilidade na organização em alguns grupos de trabalho, núcleos de pesquisa e mesas de comunicações coordenadas nos congressos e encontros, numa distinção regida pela lógica do suporte tecnológico. Ou, então, se dá uma outra divisão, bem conhecida: aquela provocada pela ruptura entre produção-mensagem-recepção. No inventário minucioso elaborado por Cristina Ponte (2004) sobre a produção teórica internacional sobre jornalismo, constatamos que o campo investigativo do jornalismo também repete os clássicos eixos pelos quais tradicionalmente são pensados os processos comunicativos em geral: os eixos da mensagem (discurso / literatura), da emissão (produção da notícia / conhecimento) e dos efeitos/recepção (sujeito receptor - sentidos - conhecimento - imaginário).

No caso particular das pesquisas que lidam com matérias jornalísticas impressas - as mais preponderantes na área, conforme detectaram Hohlfeldt e Strelow -, quero reforçar a atenção para o problema que, a partir de impressões colhidas em leitura, revisão e edição de textos científicos, pode ser identificado em muitos dos artigos publicados em revistas acadêmicas e nos trabalhos apresentados em congressos da área. Trata-se da polifonia metodológica nada esclarecedora das investigações que recorrem ao texto jornalístico. Podemos encontrar nas intenções das metodologias um arsenal de opções que, a partir de temáticas variadas da mídia noticiosa (meio-ambiente, criminalidade, escândalo político, preconceito), se propõem a verificar: os mapas cognitivos, a construção da imagem (do/da...), os posicionamentos ideológicos, a análise descritiva, a análise de representação (do/da...), a análise textual, a construção social (de...), a produção de sentido, os enfoques, as abordagens, os enquadramentos, os discursos, a análise de discurso, a análise do discurso, a cobertura 
jornalística.

Como já disseram Hohlfeldt e Strelow com relação aos trabalhos apresentados em 10 anos no Núcleo de pesquisa em Jornalismo da Intercom, muitas dessas nomenclaturas, se reorientadas de modo mais criterioso, tendem a nos levar ou à análise de discurso, ou à análise de conteúdo. No entanto, gostaria de levantar uma hipótese aqui. Muitas das pesquisas com texto jornalítico impresso estão fazendo, a partir do texto, estudos de produção da notícia. É o caso dos trabalhos que revelam, e revelam bem, via texto, as condições de apuração, como, por exemplo, se a matéria vem assinada ou não, se de correspondente ou de agência, se somente com fontes oficiais etc. Dados que mostram muito mais do processo produtivo, e que por isso o protocolo metodológico adotado ali não deveria se vincular à análise de discurso - método/teoria dos mais referenciados recentemente.

Quando Martín-Barbero (1995) propõe o deslocamento no sentido da recepção, dentro da Teoria da Comunicação, insiste que avancemos sobre a idéia condutista de etapa, que passemos a pensar o processo inteiro sem separar as instâncias de produção>meio/mensagem $>$ recepção. Não quer dizer, contudo, que o caminho seja apenas conjugar todas as etapas, pesquisando sobre um mesmo fenômeno o contexto de produção, os textos e imagens e infográficos e os modos de recepção. Nem seria, desconfio, tomar a recepção como perspectiva teórica integradora dos processos de produção, do produto e da audiência. Seria pensar fora da lógica de etapas, para além dos fragmentos recortados do circuito - o circuito da produção>produto em circulação>consumo, conforme nomeia Richard Johnson. De fato, como diz Johnson, o que mais ocorre, no caso dos produtos culturais, é que se estamos colocados em um ponto do circuito "não vemos, necessariamente, o que está acontecendo nos outros" (Johnson 1999:33).

Discordo, no entanto, do autor quando afirma que "os processos desaparecerem nos produtos" (Johnson 1999:33). Se procurarmos nos artigos publicados e/ou apresentados em congressos que pesquisam textos jornalísticos (e aí falo também de textos de telejornais e radiojornais), e que dizem trabalhar com análise de discurso e mesmo com análise de conteúdo, vamos encontrar muitas revelações sobre o «newsmaking», muito especialmente no estudo de fontes jornalísticas. Por isso, suponho que para pensar o processo jornalístico como um todo deveríamos pesquisar também como em um único ponto do circuito escolhido como objeto de trabalho podemos localizar informações que mostrem os demais. Uma vez que trato aqui das pesquisas com textos jornalísticos impressos, lembro que não estou sugerindo que tudo está no texto - e que já bastariam, então, os estudos sobre um receptor-presumido, um leitor-modelo. Além de se perceber o processo de produção da notícia no texto, poderíamos investigar e verificar o receptor na produção, a produção na recepção.

Para isso será necessário repensar as metodologias utilizadas e pensar novos procedimentos metodológicos para a pesquisa em Jornalismo. A começar, como provocação, por fazer reflexões sobre como a freqüente opção metodológica pela análise de discurso para tratamento de textos jornalísticos pode encobrir a falta de metodologias mais apropriadas de investigações nesta área. Como seria o caso de uma metodologia própria para análise de cobertura jornalística, quer dizer, quando o texto publicado pode revelar aspectos do processo produtivo da notícia, sem passar pela estreita compreensão do que entendemos por «newsmaking»; e também de outra metodologia para se investigar o texto jornalístico como narrativa antropológica, no que concerne aos estudos do imaginário na mídia noticiosa, que possibilite estudar o imaginário na produção e não apenas na recepção das notícias. Serão métodos e metodologias mais apropriadas ou mais bem empregadas que contribuirão para a consolidação das bases teóricas e epistemológicas do Jornalismo.

Talvez, para começar, ajudasse muito na compreensão do mapa das pesquisas da área se levantamentos sobre a produção científica revisassem seus modos de classificar os trabalhos, evitando misturar numa mesma apreensão tema, metodologia, técnica de coleta de dados e suporte tecnológico - a propósito, no que diz respeito ao jornalismo feito na internet, se repete agora o se deu e se dá até hoje com a classificação 
telejornalismo e radiojornalismo, mesmo no ordenamento das mesas dos congressos e encontros científicos. Há que se reestruturar essa lógica e critérios utilizados se quisermos mesmo saber o que está se passando na pesquisa em Jornalismo, do ponto de vista metodológico, teórico e epistemológico.

\section{Bibliografia:}

BERGER, Christa. (2002). Jornalismo na Comunicação. In: Tensões e objetos: da pesquisa em comunicação / org. M. H. Weber, I. Bentz e Antonio Hohlfeldt. Porto Alegre: Sulina, 2002.

(2001). A pesquisa em comunicação na América Latina. Hohlfeldt, A., MARTINO, L.C. e França, V. V. (orgs). In: Teorias da comunicação: conceitos, escolas e tendências. Petrópolis, RJ: Vozes. DUARTE, Jorge e Antonio Barros (2006). Métodos e técnicas de pesquisa em comunicação São Paulo: Atlas, 2006.

JOHNSON, Richard, Ana Carolina Escostegui e Norma Schulman (2000). O que, afinal, Estudos Culturais? Belo Horizonte: Autêntica, 2000.

HOHLFELDT, Antonio e Aline Strelow (2007). "Metodologias de pesquisa: o estado da arte no campo do jornalismo - os núcleos de pesquisa da Intercom". V Encontro Nacional de Pesquisadores em Jornalismo SBPJor, Aracaju, Se, 2007.

LAGO, Claudia e Marcia Benetti (2007). Metodologia de pesquisa em Jornalismo. Petrópolis, RJ: Vozes, 2007.

MacCOMBS, Maxwell. (2007) "Creating a new news: opportunities in the internet for broader and deeper journalism”. V Encontro Nacional de Pesquisadores em Jornalismo - SBPJor, Aracaju, Se, 2007.

MACHADO, Elias (2004). "Dos estudos sobre o jornalismo às teorias do jornalismo: Três pressupostos para a consolidação do jornalismo como campo de conhecimento". e-compós Revista Eletrônica da Associação Brasileira dos Programas de Pós-graduação em Comunicação v. 1, dezembro de 2004.

MACHADO, Márcia Benetti. (2004). "Pesquisa em Jornalismo no Brasil: dados e reflexões sobre três ambientes". II Encontro Nacional de Pesquisadores em Jornalismo - SBPJor, Salvador, 2004.

MARTIN-BARBERO, Jesus. (1995). América Latina e os anos recentes: o estudo da recepção em comunicação social. In: Sujeito: o lado oculto do receptor (org. Mauro Wilton). São Paulo: Brasiliense, 1995. MEDITSCH, Eduardo e M. Segala. ( 2005). Trends in three 2003/4 journalism academic meetings. Brazilian Journalism Research. Brasília, Br: SBPJor. v. 1, n. 1, semester 1, 2005.pp. 47-60.

MELO, José Marques de. Teoria do jornalismo: identidades brasileiras. São Paulo: Paulus, 2006.

PONTE,Cristina. (2004). Leituras das notícias; contributos para uma análise do discurso jornalístico.

Lisboa: Livros Horizonte.

RODRIGO ALSINA, Miguel (2007). "La sociosemiótica como método de investigación em periodismo". V Encontro Nacional de Pesquisadores em Jornalismo - SBPJor, Aracaju, Se, 2007.

SOUSA, Jorge Pedro (2004). Elementos de teoria e pesquisa da comunicação e da mídia. Florianópolis, SC: Letras Contemporâneas, 2004.

(2004). Introdução à análise do discurso jornalismo impresso. Florianópolis, SC:

Letras Contemporâneas, 2004.

STRELOW, Aline. (2007) “Análise Global de Processos Jornalísticos”. XXX Congresso Intercom, Santos, SP, 2007.

Vivendo com a telenovela: mediações, recepcção, teleficcionalidade. (2002). Maria Immacolata Vassallo de Lopes, Silvia Helena Simões Borelli e Vera da Rocha Resende. São Paulo: Summus, 2002. 


\section{Notas:}

Trabalho apresentado no NP Jornalismo - Encontro dos Núcleos de Pesquisa em Comunicação, evento componente do XXXI Congresso Brasileiro de Ciências da Comunicação. Natal, RN - 2 a 6 de setembro de 2008 .

(1) Acrescentaria publicações mais recentes de jornalistas como Ricardo Noblat, Carlos Dornelles, Leão Serva, Caco Barcellos, Sérgio Dávila e demais que tratam de relatos de correspondentes de guerra.

(2) Baseado em Elias Machado (2004) e Pereira \& Wainberg (1999).

(3) Realizado em novembro de 2007, em Aracaju, Sergipe, a SBPJor assim justifica a escolha do tema nos Anais do Congresso: "Um dos maiores desafios dos pesquisadores em jornalismo consiste justo em constituir e refinar metodologias apropriadas às especificidades do objeto e capazes de interpretar as particularidades do jornalismo como prática profissional (...). Objeto tradicional para a aplicação de metodologias oriundas de outras áreas do conhecimento, o jornalismo necessita, mais que nunca, abrir o debate sobre a necessidade de desenvolver metodologias próprias".

(4) De um total de 462 se quantificados, além dos estudos empíricos, os trabalhos teóricos.

(5) «Vivendo com a telenovela: mediações, recepção, teleficcionalidade».

(6) «Métodos e técnicas de pesquisa em comunicação», organizado por Jorge Duarte e Antonio Barros; dois livros de Jorge Pedro de Sousa, «Elementos de teoria e pesquisa da comunicação e da mídia»e «Introdução à análise do discurso jornalismo impresso»; e «Metodologia de pesquisa em jornalismo», organizado por Claudia Lago e Marcia Benetti.

(7) Cristina Ponte. «Crianças em notícias; a construção pelo discurso jornalístico 1970-2000», de 2005.

\section{Mini Currículo :}

Professora do Mestrado em Jornalismo da Universidade Federal de Santa Catarina (UFSC) e doutora pelo programa de Estudos Pós-Graduados em Ciências Sociais (Antropologia), da Pontifícia Universidade Católica de São Paulo. 